ference with protein metabolism. The red blood cells of rats deficient in vitamin $E$ are hæmolysed by dialuric acid.

In the final paper, Dr. L. J. Harris (Dunn Nutritional Laboratory, Cambridge) examined the literature which, despite its bulk, still leaves us without evidence for a specific metabolic role of vitamin C. Among the older hypotheses was one associating ascorbic acid with collagen formation, and also the more general theory that certain formative cells, such as osteoblasts, show reduced activity; in these cells the vitamin has been found to be concentrated in the Golgi apparatus.

Recent studies have established that the metabolism of tyrosine is affected. The intact scorbutic animal (including man) fails to oxidize completely additional tyrosine fed to it, and tissue slices from deficient animals oxidize tyrosine less rapidly than normal.

The extent of conversion of folic acid into folinic acid is reduced in deficiency of the vitamin, a finding which might explain a suspected connexion between scurvy and anæmia.

The adrenal gland, the original source of SzentGyorgyi's 'hexuronic acid', contains high concentrations of the vitamin, and investigations are in progress to see whether any specific relation exists between the activity of the adrenal cortex and the function of the vitamin.

The great majority of animals can synthesize vitamin C, but, although glucose is known to be its precursor, it is still not known whether synthesis is a property of all cells of the body, or whether certain tissues are specialized for this purpose; similarly, the function of the vitamin in plants is still obscure.

J. S. D. BACON

\section{ROYAL SOCIETY MOND LABORATORY, CAMBRIDGE}

\section{By D. D. SHOENBERG}

$\mathrm{T}$ HE Royal Society Mond Laboratory was formally opened on February 3, 1933, by Mr. Stanley Baldwin, then Chancellor of the University. The twentieth anniversary of this occasion was recently celebrated by a party, preceded by demonstrations of phenomena at very low temperatures. In this brief review of the work of the Laboratory, it is appropriate first to recall how much it owes to the initiative and enthusiasm of Dr. P. Kapitza, who was its first director. Soon after Kapitza came to Cambridge in 1921, he became interested in measuring the curvature of $\alpha$-ray tracks by magnetic fields, and this led him to think of the possibility of using magnetic fields much larger than those usually available in electromagnets but lasting for only a small fraction of a second. By limiting the duration of flow of a current in a coil to 1/100 sec., much higher currents can be used without producing too much heat, while at the same time $1 / 100$ sec. is usually ample for the full establishment of any magnetic effect to be studied-thus, for example, an $\alpha$-particle spends only about $10^{-9} \mathrm{sec}$. in the apparatus.

Kapitza first applied this principle in practice by discharging a specially designed accumulator battery through a coil, and breaking the current within a very short time of making by various automatic devices; by this means he studied $\alpha$-ray curvatures, and later the Zeeman effect. The success of these preliminary experiments, in which fields of order 100,000 gauss were obtained, led him to think of more reliable methods of achieving still greater fields, and eventually he set up a large electric alternator which, during half a cycle of its operation, was connected across a coil to give a field of 300,000 gauss over a volume of several cubic centimetres. The equipment required considerable space, not only because of the large size of the machine and control gear, but also because, in order that the mechanical shock of the discharge should not disturb the delicate recording oscillographs, these had to be placed at a distance of about thirty yards away from the generator-a distance greater than that travelled by the shock wave in $1 / 100$ sec. Space was provided on a site now occupied by the Department of Physical Chemistry, and Kapitza carried out $a$ series of pioneer researches on various magnetic properties of matter-particularly the change of resistance of metals in a magnetic field, and also a study of magnetostriction and susceptibility. Many of the effects studied became much more striking at lower temperatures, and this led Kapitza to construct a hydrogen liquefier and to think of a helium liquefier in order to exploit more fully his high-field technique. It became clear that more laboratory space would be required to house such a complex of magnetic and cryogenic research, and the Royal Society made available funds from a bequest of Ludwig Mond in order to build a new laboratory suitable for the purpose, and at the same time appointed Kapitza to be Messel professor and director of this laboratory.

The special requirements of the Laboratory led to an unorthodox but attractive design of building, the central feature of which is a large hall for the highfield equipment, around which are grouped various smaller rooms for research and for the technical services (liquefiers, workshop and machine room); apart from some office accommodation and a conference room on an upper story at one end, the laboratory is mostly on one floor. The central hall later lost its primary function; but I think everyone who has worked in the Laboratory will agree that it has served a useful secondary function in lessening the isolation of the individual research rooms and providing a spacious atmosphere which is, perhaps, lacking in the more conventional type of laboratory built around narrow corridors.

As soon as the new Royal Society Mond Laboratory had been opened and the various machines installed, Kapitza set to work to build a helium liquefier. In characteristic style he preferred to design an entirely new type of machine rather than copy existing ones, and he was successful in developing a liquefier in which cooling below liquid-nitrogen temperatures was achieved by an expansion engine, and no liquid hydrogen was used (although, of course, liquid hydrogen was available from a separate liquefier if required for investigation at higher temperatures). It is interesting to note that Kapitza's machine was the forerunner of the Collins helium liquefier, which has become commercially available, and has been largely responsible for the enormous development of cryogenic research in the United States in recent years.

Just when it seemed that the Laboratory was ready to carry on full-scale research at low temperatures and high magnetic fields, a serious setback occurred when Kapitza was unable to return to Cambridge 
from a visit to the U.S.S.R. When it became clear that this situation was likely to continue, it was eventually decided to sell his high-field equipment to the U.S.S.R. so that Kapitza could carry on his work in Moscow, and to develop the Cambridge laboratory primarily as a cryogenic rather than a magnetic laboratory ; J. D. Cockeroft, who had been closely associated with Kapitza in much of his early work, was put in charge of the laboratory. Up to this time, cryogenic research at the temperatures made available by the use of liquid helium had been almost an exclusive monopoly of the Kamerlingh Onnes Laboratory at Leyden, though, on a smaller scale, work had been going on in Toronto, Berlin, one or two centres in the United States, and had just started in Oxford. A number of quite new and unexpected phenomena, such as superconductivity and the $\lambda$-transition in liquid helium, had been discovered in Leyden; but these were, as yet, little understood, and there was still plenty of scope for relatively simple experiments designed to investigate points of principle.

During the next few years work, the policy of carrying out such experiments yielded handsome dividends. J. F. Allen and various collaborators (A. D. Misener, J. Reekie and E. Ganz) took up the study of the properties of liquid helium below the $\lambda$-point. Investigation of the anomalously high heat conductivity led to the discovery of the striking 'fountain effect', which showed that the heat flow was intimately associated with material flow. This was followed by the discovery that the liquid could flow in fine channels with an almost complete absence of viscosity, and this led eventually to the concept of a superfluid component of liquid helium. By a curious coincidence, Kapitza, in his new Moscow laboratory, had turned aside from his investigations at high magnetic fields and made the discovery of superfluidity in fine channels independently at the same time. D. Shoenberg took up various questions of the magnetic behaviour of superconductors which, following the discovery of the Meissner effect, were beginning to excite interest; later, his studies of the magnetic susceptibility of small superconducting particles in mercury colloids, in parallel with experiments by E. T. S. Appleyard and others on superconducting thin films, proved the reality of the small depth of penetration (of order $10^{-5} \mathrm{~cm}$.) of a magnetic field into a superconductor, which had been envisaged in the theory of $\mathrm{F}$. and $\mathrm{H}$. London, and demonstrated that this depth of penetration was strongly dependent upon temperature. At the same time, J. Ashmead had designed water-cooled coils to give steady fields of up to 50,000 gauss and used them in the development, of the technique of adiabatic demagnetization, which had been recently opened up in Leyden and in Oxford, as a practical method of working at temperatures below $1^{\circ} \mathrm{K}$

All this work was interrupted by the Second World War, and for the next six years the Laboratory was turned over to various researches for the defence ministries. Late in 1945, cryogenic research was started again, first under Allen's direction, and since 1947, when Allen was appointed to the chair of natural philosophy at St. Andrews, under Shoenberg. Perhaps the most striking advance since the War has been the application, by A. B. Pippard, of the radar techniques developed during the War to problems of superconductivity. $\mathrm{He}_{\Theta}$ has studied the behaviour of supersonductors at very high frequencies-where the resistance is no longer zero, but drops only gradually as the temperature is lowered -and has developed methods of studying the depth of penetration which are not only more accurate than the colloid method and other 'static' methods developed in the Laboratory since the War but also lend themselves better to a variation of physical conditions such as crystal orientation and purity. These investigations have reached a stage where the London theory, which provided such a valuable interpretative guide in the past, is beginning to prove inadequate, and Pippard's results are indicating the direction in which the theory needs modification. Other researches on superconductivity by E. R. Andrew, T. E. Faber, J. M. Lock and D. Shoenberg have cleared up some of the puzzles connected with the intermediate state in the transition from the superconducting to the normal phase, and have enabled the magnitude of the surface tension between the phases to be estimated. New data have also been obtained by G. T. Pullan on the behaviour of the thermoelectric power in the transition and by J. K. Hulm and B. B. Goodman on the thermal conductivity of superconductors; the adiabatic demagnetization technique is being used to extend the latter data into the range below $1^{\circ} \mathrm{K}$., which is of particular interest theoretically.

A by-product of Pippard's work on superconductors has been his study of the anomalous skin effect in normal metals, which sets in when the electron mean free path becomes comparable with the skin depthas occurs at very high frequencies and low temperatures. Pippard's semi-quantitative explanation of the effect was developed in detail by G. E. H. Reuter and E. H. Sondheimer, and comparison with the more detailed experiments later carried out by R. G. Chambers has provided new information about the parameters which enter into the electron theory of normal metals. The de Haas - van Alphen effect (a periodic variation of magnetic susceptibility with field strength) provides somowhat similar information, and during the past fow years Shoenberg has discovered this effect in a number of metals. Quite recently he has developed a new method of studying the effect at high fiolds produced by discharging a large condenser through a coil, thus on a modest scale reviving the Kapitza tradition in the Laboratory.

Work with liquid helium since the War has been carried on by K. R. Atkins (now in charge of the Toronto cryogenic laboratory), D. V. Osborne, A. C. Hollis-Hallett and C. E. Chase. One of the most important researches has been the measurement of the speed of 'second sound' down to about $0.1^{\circ} \mathrm{K}$., which proved to show just the rise predicted by Landau's theory. Other work has included studies of the helium film, the hydrodynamic properties of liquid helium and the absorption of sound. Rather as in superconductivity, here too, the further the experiments are pushed the more evident does it become that existing theories are in need of improvement.

In the course of all these researches the essential simplicity of experiments which was characteristic of the early days of the Laboratory has to some extent been lost with the necessity for more accurate measurements of less easily studied properties. More and more complicate devices have had to be accommodated in ever larger liquid-helium 'dewars', while at the same time the number of projects going on simultaneously has also increased. For these 
reasons the Kapitza liquefier which had rendered such excellent service for many years was abandoned in 1949, when Ashmead built a larger liquefier, working on the more conventional cascade principle, but yielding $3 \cdot 7$ litres per hour instead of the previous 1.8. This gain in yield was achieved by making use of the full capacity of the hydrogen and helium compressors of the Laboratory, and particular attention was paid in the design of the liquefier to ease of servicing. At present, as many as six or seven separate 'helium runs' can be carried on simultaneously on each of the two 'helium days' every week, and it is hoped that the flexibility of experimenting will be still further improved soon, when a large liquid-helium storage vessel is brought into use, so that it will be possible for liquid helium to be used at any time.
In such a brief account as this of twenty years work, it has been scarcely possible to do more than point out the main trends; and inevitably some of the individual researches-such as the experiments on paramagnetism before the War by H. M. Barkla and E. S. Shire, J. Ashmead and J. Reekie and more recently by C. G. B. Garrett-have found no mention. In its main lines of research, on superconductivity and liquid helium, the work of the Laboratory has helped in clarifying many tangled questions; but though in some ways it is now clearer what it is that has to be explained, the underlying fundamental theories are still far from developed. This is an attractive situation for the experimenter in the challenge it offers, and it is hoped that the Laboratory will play a part in the future in reaching the deeper understanding which is still lacking.

\section{NEWS and VIEWS}

\section{Wool Textile Engineering at Leeds: \\ Dr. Alfred H. Nissan}

AN interesting development in the Department of Textile Industries of the University of Leeds is the recent appointment of Dr. A. H. Nissan as the first holder of the research chair of wool textile engineering, which was endowed in 1947 by the Wool Industry Surplus Cloth Corporation and the National Wool Textile Export Corporation with donations amounting to $£ 52,500$. Dr. Nissan is a graduate in chemical engineoring of the University of Birmingham; he was awarded the Sir John Cadman Medal and the Burgess Medal and Prize of the Institute of Petroleum. After carrying out research for the degree of $\mathrm{Ph} . \mathrm{D}$., he was appointed to the staff as lecturer in petroleum production engineering in 1939 and proceeded to the degree of D.Sc. in 1943. During the War he worked under the direction of Prof. F. H. Garner on flamethrower problems, including the hydrodynamics of flow of complex visco-elastic systems and chemical engineering problems connected with the development of a novel flame-thrower fuel. In association with L. Grunberg, he also devised an interesting method of making sea-water potable by removing the chlorine ion with silver oxide and the sodium ion with uranium oxide. After the War, Dr. Nissan's attention was turned to combustion processes in diesel engines and the properties of detergent oils as lubricants, until he was appointed head of the Central Research Laboratories of the Bowater Paper Corporation, Ltd., in 1947. There he has had the interesting and setisfying experience of developing a strong and successful research team from the smallest beginnings; he should find equal opportunities in the work of the new chair to which he has been appointed.

\section{Imperial College of Tropical Agriculture : Dr. G. A. C. Herklots}

Dr. G. A. C. Herkuots, who is succeeding Mr. H. J. Page as principal of the Imperial College of Tropical Agriculture (see Nature, 170, 564; 1952), studied at Leeds and Cambridge under J. H. Priestley, Walter Garstang and F. F. Blackman. In 1928 he went to Hong Kong University to take charge of the new Department of Biology. His first interest in natural history found expression in the ten volumes of the "Hong Kong Naturalist" and in books on trees, orchids, natural history and birds. $\mathrm{H}$ is interest then extended to economic products; and the
Journal of the Hong Kong Fisheries Research Station, a book on food fishes, and another on vegetable cultivation, were the practical outcome. The problem of nutrition appealed to him, and he was fortunate in being seconded to Dr. B. S. Platt's nutrition survey unit in Nyasaland for six months in 1939. On his return to Hong Kong his services were lent to the Government, first in connexion with firewood supplies; later, as scientific adviser to the Food Controller, he helped in the establishment of a siege reserve for $1,800,000$ people. Following fortythree months internment by the Japanese, when he had practical experience of poverty and malnutrition, he was entrusted with the task of re-organizing the fishing industry and organizing vegetable production on a large scale in Hong Kong. (Hong Kong now sells wholesale 30,000 tons of fish and more than 40,000 tons of locally produced vegetables annually.) As secretary for development he was responsible for the creation of a Department of Agriculture and for the administration of departments of gardens, forestry and of the fish and vegetable marketing organizations. Since 1948 he has been secretary for Colonial agricultural research at the Colonial Office-an appointment which has enabled him to visit most of the Colonies of the British Empire.

\section{Instruments and Accessories for Use with Radio- active Isotopes}

THE second edition has been published of "Instruments and Accessories for Radio-Isotope Applications", a useful brochure for the potential users of radioactive isotopes, edited by Dr. Denis Taylor and A. G. Peacock (pp. 20. London: Sciontific Instrument Manufacturers' Research Association, 1952; free). Without detailed knowledge, the selection of suitable electronic equipment may be very difficult, and the details given of the various detector elements and associated equipment used for radioactive assay and radiation monitoring, together with the names and addresses of manufacturers, will therefore be of considerable assistance. The brochure is divided into sections, dealing with assay instruments, including Geiger, proportional, and scintillation counters, and ionization chambers; monitoring instruments; geological survey prospecting equipment ; special instruments, including material-thicknesses gauges, pulseamplitude analysers, D.c. amplifiers and oscilloscopes; and accessory equipment, covering isotope containers and handling equipment, laboratory 